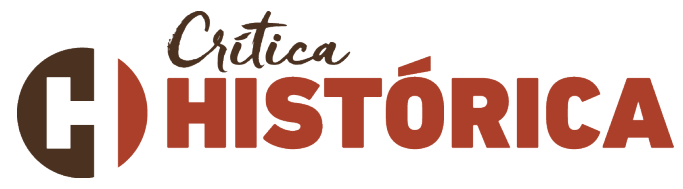

\section{Piratas do rio: roubos, furtos e outros crimes a bordo e nas margens da "Região de Manaus"}

\author{
Pirates of the River: robberies and other crimes on board and on the banks of the \\ "Manaus Region"
}

\section{Leno José Barata Souza*}

Resumo: O artigo tem com objetivo recuperar e discutir alguns crimes sociais ocorridos pelas aguas fluviais da chamada "Região de Manaus", tendo como foco os delitos de furtos e contrabandos ocorridos entre as décadas de vinte e sessenta do século passado, tempo da grave crise da borracha amazônica que, além da economia, foi também fator preponderante sobre as questões sociais e de sociabilidades do lugar. Destacamos que, mesmo resguardando as peculiaridades históricas, às antigas experiências dos piratas da era moderna serviu de inspiração e referencia teórica para a abordagem desses crimes em uma Amazônia contemporânea. Para tanto, nos valemos de fontes orais e, em maior relevo, das fontes impressas como os jornais publicados em Manaus, centro daquela "Região".

Palavras-chave: crimes, piratas, Região de Manaus

Abstract: The article aims to recover and discuss some social crimes that occurred in the fluvial waters of the so-called "Manaus Region", focusing on the crimes of thefts and contraband that occurred between the twenties and sixties of last century, time of the severe Amazon rubber crisis that, in addition to the economy, was also a preponderant factor on the social and and sociability of the place. We emphasize that, even preserving the historical peculiarities, the ancient experiences of the pirates of the modern era served as inspiration and theoretical reference for the approach of these crimes in a contemporary

\footnotetext{
- Pós-doutor em História pela Universitá di Venezia Ca’Foscari. O artigo é resultado de algumas ideias inconclusas de nossa tese: "Cidade Flutuante: uma Manaus sobre as águas (I920-1967)", defendida em 20I0, com Bolsa CNPQ e PDEE da CAPES na Universidade de Roma, La Sapienza.
} 
Amazon. To do so, we use oral sources and, more importantly, printed sources such as the newspapers published in Manaus, the center of that "Region".

Keywords: crimes, pirates, Region of Manaus

Os piratas dos rios e os rios dos piratas, a guisa de uma introdução

"Você está fora do mapa amigo, aqui só há monstros"

"Bando de ladrões", "vermes", "vagabundos", "celerados que nada têm de humano", é essa a tônica da imagem e das letras do "Uma história dos piratas", ${ }^{2}$ obra de 1724 coeva ainda aos últimos tempos em que esses criminosos singravam os mares, espreitando naus desavisadas e portos desguarnecidos que pudessem resultar em ricos butins para homens e mulheres que, por variadas razões, tinham abraçados a pirataria como fonte de sobrevivência, riquezas, prazeres, aventuras e liberdade todas consagradas, ou caricaturadas, pelas mais diferentes artes: de cançonetas populares a óperas, do teatro ao cinema, do folhetim a história cientifica que acabaram formando e projetando imagens e imaginários dos piratas no tempo.

Suas ações, ainda que institucionalmente criminalizadas e condenadas a partir da modernidade industrial capitalista, fins do século XVIII, ${ }^{3}$ permaneceram como inspirações para outros crimes que seguiram no tempo, atormentando e alarmando as sociedades dos estados modernos. Logicamente que os piratas contemporâneos são outros, mas a essência e os objetivos de suas ações: furtos, roubos, desvios, abordagens e fugas nos remeteram as experiências históricas da pirataria de outrora.

Por estes vieses foi que resolvemos propor aqui determinados delitos: a bordo, nas margens e sobre as águas de alguns rios amazônicos, ocorridos entre as décadas de vinte e sessenta do século passado no estado do Amazonas, a luz do modus operandi daqueles

\footnotetext{
ITrecho do filme "Piratas do Caribe: a maldição do Pérola Negra".

${ }^{2}$ Trata-se de uma obra, cuja autoria ainda hoje é fruto de discordância entre os estudiosos. O historiador Luciano Figueiredo, prefaciando a edição digitalizada de 2008, defende Daniel Defoe como autor, o mesmo que se notabilizou pela obra Robinson Crusoé de I717. Kenneth Maxwell preferiu manter a discussão em aberto, sobretudo a partir deu um desconhecido capitão Charles Johnson, para alguns, como David Cordingly, a obra não se ligaria a Defoe (MAXWELL, I990, p. 75).

${ }^{3}$ Ainda que seus criminosos sejam de outra natureza, sublinho, como fonte de inspiração, a clássica obra,

"Bandidos" de Eric Hobsbawm, a quem dedico esse artigo, "In Memoriam", ever!
} 
antigos "lobos dos mares". Então, quem seriam os nossos piratas rastreados na imprensa local da época?

No que pudemos apurar nas linhas e entrelinhas dessa mesma imprensa é que nossos piratas, de início eram, como na antiga pirataria, homens, muitos bem jovens e de alguma forma dependentes de serviços e negócios ligados aos rios e igarapés da região como canoeiros, catraieiros, pescadores, atravessadores, marítimos, foguistas, tripulantes de embarcações que, por diferentes motivos, foram flagrados em crimes de roubos, furtos, desvios de mercadorias e contrabandos pela orla, portos e aguas fluviais do Estado.

Eram frequentadores assíduos das crônicas e colunas policiais que tanto inquietaram a sociedade amazonense, obrigando as autoridades locais, de tempos em tempos, a realizarem ferrenhas contraofensivas, como a "blitz-krieg" de 1948 do Gabinete de Investigação e Capturas (GIC) da policia “(...) contra os ladrões que infestam o rio e igarapés da cidade (...)", 4 celebrada na imprensa que diuturnamente cobrava ações efetivas das autoridades.

Além de "ladrões", eram comumente referendados na imprensa por vagabundos, desocupados, meliantes, espertalhões, desabusados, lunfas, mais eventualmente por piratas, ou, potencializando tais referências genéricas e incriminadoras, por "magote de desocupados" como os surpreendidos pela policia “(...) na pratica de jogos prohibidos" pelas embarcações e igarapés de Manaus e que foram parar na coluna "Coisas Policiaes" do Jornal do Comércio, ${ }^{5}$ e na manchete, não menos desqualificadora, por "Os ratos do porto agindo" em “(...) vapores e gaiolas ancorados nas immediações do porto, pelos braços navegáveis adjacentes". ${ }^{6}$

As informações pontuais, sentenciosas e, sobretudo genéricas dos jornais dificultam precisarmos mais afundo seus rostos, mesmo porque, a maioria desses crimes não era resolvida pela polícia, também era incomum as noticias sobre as elucidações dos delitos na imprensa, mais preocupada com o crime em si, dificultando a elaboração de um perfil social para tais criminosos, “a tarefa de identificar os 'rostos' esta cheia de, no mínimo, obstáculos e problemas" (RUDÉ, I99I, p.I2). ${ }^{7}$

De qualquer forma, tanto pela lei quanto pela moral da época, "ratos do porto" e "magote de desocupados" são índices históricos que nos ajudam, ao menos, entrever aqueles homens, criminosos dos rios, sempre a espreita de embarcações, pessoas,

\footnotetext{
${ }^{4}$ O Jornal. Manaus, 02 de fevereiro de 1948.

${ }^{5}$ Jornal do Comércio. Manaus, 23 de julho dei93o.

${ }^{6}$ O Jornal. Manaus, "Registro Policial", o7 de julho de 1932.

${ }^{7}$ Dificuldades estas aumentadas pelo não acesso a uma documentação policial e jurídica dos casos, ou porque não é permitida ao público, ou, o que é mais comum, pelo completo extravio dos documentos.
} 
mercadorias e dinheiro, lançando mão de estratégias e artimanhas incriminadas e condenadas como as que vitimaram o agricultor Joaquim Manoel de Oliveira que teve a "sua Morena", furtada da rampa do Mercado Público de Manaus, margeada pelo Rio Negro.

Tratava-se de sua pequena canoa, “(...) surrupiada d'aquella rampa, havia poucos dias, por um desses piratas desabusados que andam operando em nosso quadro" que, para alivio e sorte de Manoel, foi flagrado na mesma rampa, calmamente a bordo de sua "Morena". O tal "pirata" respondia por Antonio Faria, menor de idade, que ainda tentou, “(...) em voz desconcertada (...)”, rebater as acusações de Joaquim que “(...) não querendo suscitar um incidente com o amigo do alheio (...)", o denunciou a policia que prendeu o jovem "pirata" e devolveu a embarcação para seu legitimo dono. ${ }^{8}$

Mas, onde mais precisamente atuavam esses "desabusados piratas"? Seus espaços de atuação são mais precisos do que seus rostos.

Em maior relevo agiam pela costa e águas pluviais do Rio Negro e igarapés de Manaus, principal cidade do estado e que mesmo em tempos de configurada crise econômica da borracha, iniciada pós-Primeira Guerra quando o Amazonas perdeu definitivamente o monopólio do produto para Ásia, a capital permanecia como a cidade politica, comercial e demograficamente mais importante do estado, lugar promissor tanto para trabalhos, serviços e negócios, como para diferentes crimes como os que, a partir dos rios e igarapés, sacudiam Manaus como um todo que, a época, possuía fronteiras bem diferentes das que hoje conformam a cidade.

Antes de esgaçarmos os limites, abordamos as aguas da capital propriamente dita formada por três bacias hídricas que cortam Manaus: Bacias de São Raimundo (ou Cachoeira Grande), Central (ou do Rio Negro) e Educandos (ou Cachoeirinha) que juntas somam I6I,I5 $\mathrm{km}^{2}$. Levando-se em conta que o perímetro urbano de Manaus tinha um total de $229,5040 \mathrm{~km}^{2}$, podemos ter uma ideia do alcance das águas fluviais na cidade e do território de ação e movimentação dos "piratas" locais que o mapa abaixo potencializa:

\footnotetext{
${ }^{8}$ Jornal do Comércio. Manaus, "Os Buliçosos”, 27 de janeiro de I920. Grifo nosso.
} 


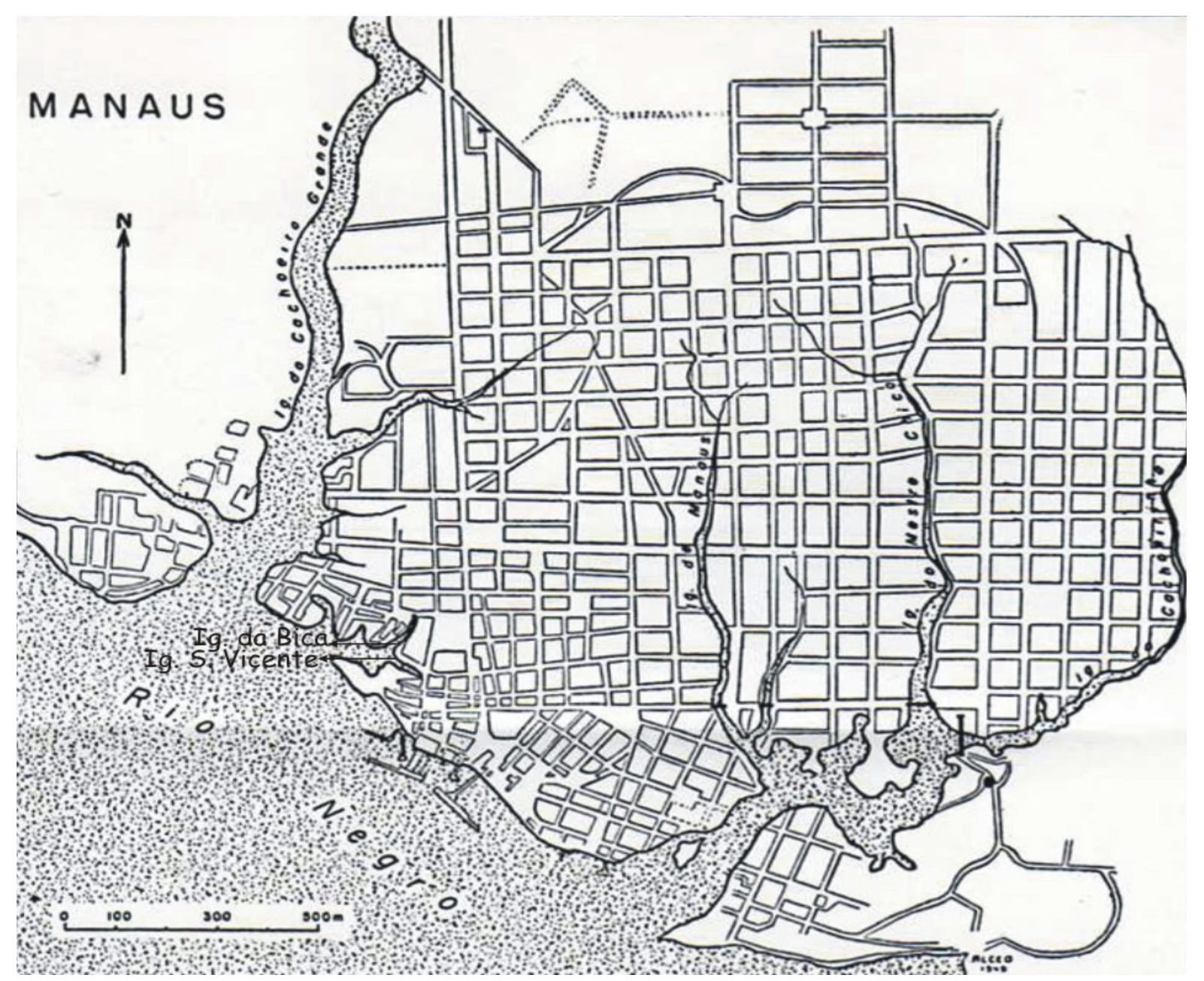

Figura I: Planta das "Ruas de Manaus".

Fonte: Revista Brasileira de Geografia, julho-setembro de I949, p. 393.

Por outro lado, ao tempo do mapa acima, Manaus alcançava também outras fronteiras, avançando sobre outras águas do estado. O estudioso local, Agnello Bittencourt (1985, p.I4 e I7I), em I925, traçou para a capital uma área de $47.874 \mathrm{~km}^{2}$, dividida em II sedes distritais, mais de quatro vezes os seus limites atuais (II.408 $\mathrm{Km}^{2}$ ). Em 1938 foram criados em Manaus mais dois distritos: 0 IO ${ }^{\circ}$ distrito do Careiro e o I distrito de Airão no Rio Jaú.

O distrito do Careiro, particularmente, era formado pelas Ilhas do Careiro e Manaquiri banhadas pelo Rio Solimões/Amazonas e pelos Paranás do Cambixe, Careiro e Barroso, destacando-se em seu interior os Lagos dos Reis, Manaquiri e Janauacá, totalizando uma cidade de $84.569 \mathrm{~km}^{2}$ (Série Amazoniana, 1942, p.I3), ${ }^{9}$ quase oito vezes a

\footnotetext{
${ }^{9}$ Trata-se de um estudo quinquenal de governo (I937-I94I), apontando para Manaus uma divisão territorial em 03 distritos e 13 Zonas Distritais. Até 1938, o distrito do Careiro ligava-se ao Município de Manacapuru. Em 1955, tanto Careiro como Airão são desmembrados de Manaus passando a condição de municípios autônomos. As separações, todavia, continuaram de difícil assimilação para os moradores do lugar,
} 
dimensão atual, assumindo formas da grande "Região de Manaus", nomeada e cartografada, em 1956, pelo geógrafo Lúcio de Castro Soares que também a reproduziu pelas linhas do mapa a seguir:

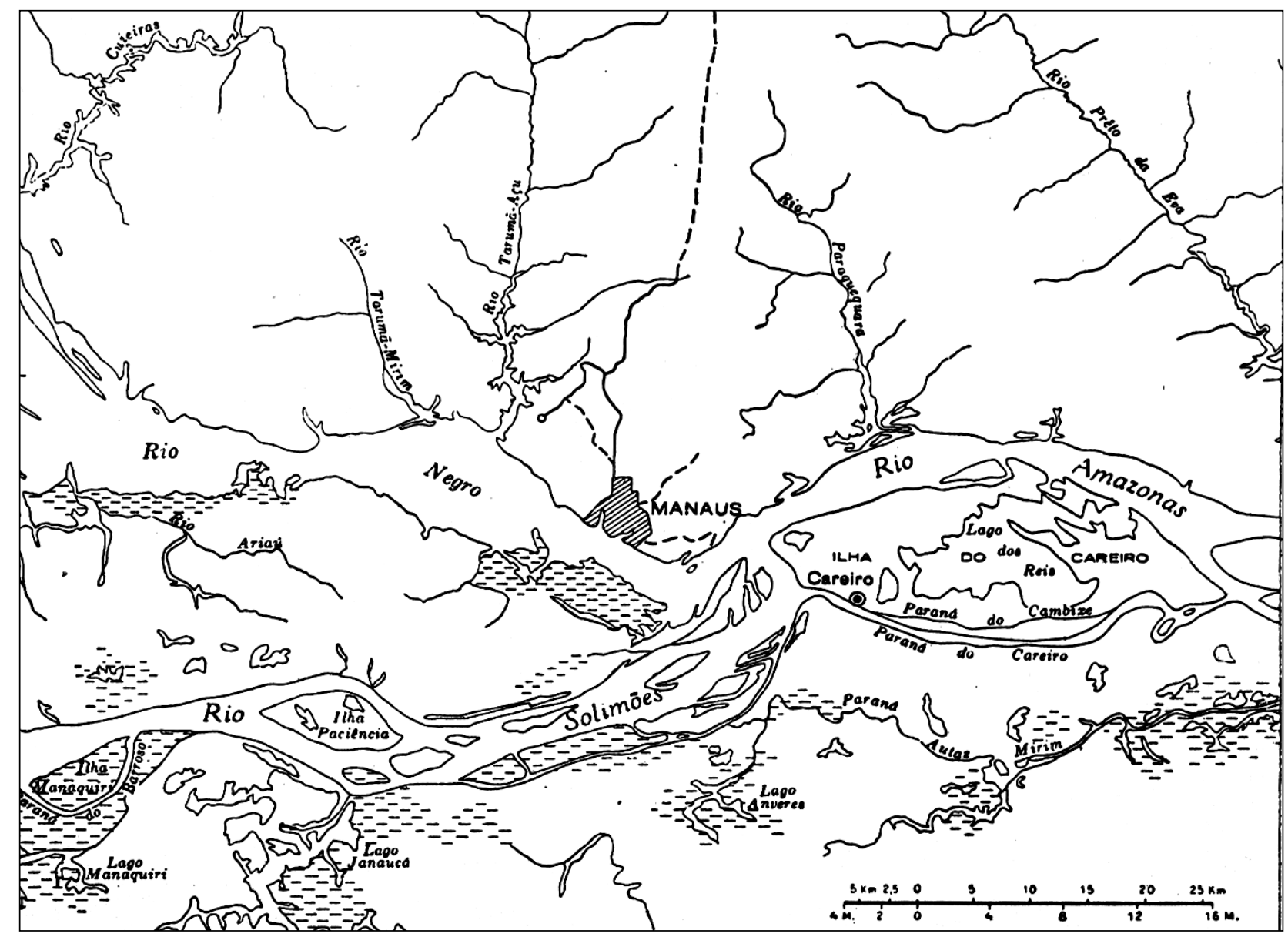

Mapa I: Antiga Região de Manaus.

Fonte: (SOARES, I956, p. 223).

Como o distrito de Airão no Rio Jaú é afluente do Rio Negro que, por sua vez, é afluente do Amazonas, a atual capital amazonense, a época que aqui nos interessa, se projetava tanto sobre a margem do Rio Negro, como do Amazonas, serpenteando por lagos, paranás, furos, ilhas e igarapés que formavam um labirinto liquido, amplamente estratégico e conveniente e que só os moradores do lugar conheciam. Conhecimentos estes dos quais se valiam tanto os "piratas" em suas ações de abordagens, fugas, desvios e esconderijos, como os agentes policiais em suas caçadas e "guerras relâmpagos" contra aqueles criminosos.

acostumados com as relações sociais, culturais, econômicas e político/administrativas que os ligavam a Manaus. Assim, nesse livro, a Manaus que narramos, grosso modo, comporta tais limites. 
Assim, "o espaço do mapa é um espaço; o espaço real vivido é o território" (ROLNIK, 200I, p. I42), carregado de valores e signos próprios que animam uma nervosa assinatura cultural, em cujas linhas se flagra uma cartografia de ações e reações humanas que potencializam os cenários naturais e os marcos político-administrativos como paisagens sociais, redes de acordos e disputas, acabando por desafiar as leis oficiais, as memórias hegemônicas e os projetos vencedores.

\section{A bordo e nas margens}

Ainda que não devamos fazer uma relação simples e automática entre crise econômica e crimes sociais, pensamos que os desdobramentos daquela: achatamentos dos salários, carestia, inflação, desabastecimento e desemprego podem sim levar, ou obrigar homens e mulheres a se lançarem no mercado oficioso de serviços como de atravessadores, marreteiros e ambulantes, ou ainda, engrossar as estatísticas de crimes mais graves como o de furtos, roubos, desvio de mercadorias e contrabando, típicas práticas de pirataria das quais muitos homens, inclusive alguns trabalhadores, operários, profissionais, poderiam se valer frente às prementes necessidades de sobrevivência marcada tantos pelos expedientes incertos dos subempregos, constrangimentos e humilhações da mendicância, como pelos riscos na pirataria pelos caminhos e descaminhos dos rios, velhos conhecidos desses homens.

Nesse sentido, Antonio Felix Carvalho, solteiro de 26 anos, seringueiro desempregado do Rio Madeira, foi internado como indigente pela "inspectoria da saúde do porto", seu caso foi uma das notas das "Coisas Policiaes" do Jornal do Comércio. ${ }^{\text {Io }}$ A partir da década de trinta as manchetes alarmantes sobre a situação de penúria econômica e social do estado se tornaram uma constante nas páginas dos periódicos, bastando, para tanto, acompanhar as noticias, em letras garrafais de primeira página: "O problema da miséria no Amazonas", "Mendigos”, “A fome esta tomando conta da cidade”, “Miséria e desolação, é o panorama do interior do Amazonas", "Duras e tristes verdades, fome, miséria e doenças, e assim prossegue a vida no Amazonas". ${ }^{\text {II }}$

A primeira das longas reportagens acima informa sobre uma "romaria de mendigos" pelo centro de Manaus. Vários desses homens abordaram um dos colaboradores da folha, “(...) estavam aflictos, procurando trabalho, já desesperançados de

\footnotetext{
${ }^{10}$ Jornal do Comércio. Manaus, 25 de março de 1929.

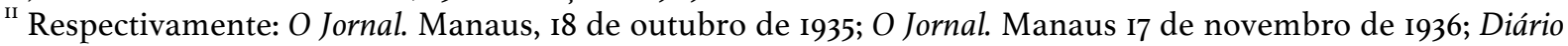
da Tarde. Manaus, 2I de junho de 1946; Diário da Tarde. Manaus, o9 de julho de I946; Diário da Tarde. Manaus, I3 de julho de 1946.
} 
obter alguma cousa para suavizar a sua situação". O panorama de miséria e desolação do interior, traçado pelo Diário da tarde, sem dúvida que influiu na vinda do seringueiro Antonio Felix para Manaus, onde caiu, ou teve que cair, na indigência.

Não sabemos se algum daqueles homens "desesperançados", ou outros, como o seringueiro Antonio, se valeram de ações criminosas, como a "pirataria" nos rios, para amenizar suas dramáticas situações. No entanto, temos aí um canteiro social propicio para aqueles fins, regado cotidianamente pelo drama de necessidades mínimas de sobrevivências não satisfeitas pelo estado como casa, comida e saúde, pelo contrário, o que se via eram as "Duras e tristes verdades, fome, miséria e doenças (...)" da vida no Amazonas.

Para nos aproximarmos mais desse contexto social, tanto nos aprofundamos nos textos dos periódicos de Manaus, como conjuntamente também levantamos fontes orais na forma de entrevistas com antigos moradores da capital, especialmente com ex-moradores da Cidade Flutuante de Manaus, tema de nossa tese (BARATA SOUZA, 20Io).

Quando da pergunta sobre roubos, furtos, assassinatos, contrabandos, ou outras contravenções na Manaus de outrora, esta, a luz da memoria dos entrevistados, é reconstruída como um lugar de serenidades e segurança, tônica das respostas entre os I4 entrevistados com os quais trabalhamos ao longo do doutorado.

Se a memória é primeiramente sensível ao presente, a semelhança das respostas é uma consequência da Manaus violenta e perigosa que hoje todos nós vivenciamos. Mais uma vez foi da cidade atual que os entrevistados partiram para recuperar os crimes da cidade na qual viveram e trabalharam entre as décadas de 1930 e I960. Sebastião Garcia nos respondeu de imediato: "hoje em dia, pra aquela minha época aqui, tá diferente e horrível"; ${ }^{12}$ Creuza de Andrade foi mais enfática ainda: "Não havia desavença lá, só sei que era assim". ${ }^{13}$

Assim, ao longo das conversas, a capital de hoje com seus sérios problemas de segurança pública, deixando a mercê da própria sorte centenas de moradores, sempre se contrapôs a Manaus de antes, tornando-a, por isso, mais serena e cordial, condizente com a cidade pequena, pacata, espelho do antigo "porto de lenha" comum e nostalgicamente reconstruído nas narrativas orais.

Não insistíamos porque duvidávamos das histórias de tranquilidade que os entrevistados, em regra, lembravam, mas as crescentes necessidades e demandas sociais entre os habitantes do Estado, como nos sinaliza as manchetes jornalísticas acima, deviam

\footnotetext{
${ }^{12}$ Entrevista. Manaus, 12 de fevereiro de 2006. Todas as entrevistas foram feitas pelo autor na cidade de Manaus.

${ }^{13}$ Entrevista. Manaus, I2 de setembro de 2008.
} 
motivar disputas por trabalhos e serviços flagrados na imprensa local, nos levando a colocar em cheque a tradicional mansidão dos moradores e a serenidade do lugar, comumente reiteradas pelas memórias das fontes orais.

Para além da utópica e ultrapassada "veracidade" das fontes, nos move compreender a diferença de suas naturezas que, se bem confrontadas, ajuda a nos aproximar melhor e a entrever mais claramente o objeto de estudo. Às narrativas impressas representam um discurso de um tempo único, cujos eventos ficaram cristalizados em suas páginas. Diferente dos discursos orais em que os acontecimentos vão e vem no tempo sendo pesados, medidos, comparados, construídos, reconstruídos e destruídos, projetando, finalmente, não apenas uma imagem do que se viveu, mas ainda do que se desejou viver.

Sobre roubos e furtos, por exemplo, o entrevistado Francisco da Silva "disparou" uma sequencia de "nãos" como uma espécie de "mantra" que procuram reafirmar a cidade pacata de antes: "Não, não existia naquele tempo, naquele tempo, num tinha violência, naquela época, num existia violência", tanto que, seguiu respondendo:

Podia dormir com a porta aberta, não existia roubo, era muito bom naquela época, não tinha roubo, você deixava sua canoa amarrada com corda lá no flutuante (sua residência), amanhecia do mesmo jeito, ninguém roubava. Então não tinha roubo, não existia violência. ${ }^{14}$

Significativo, porém que nem havíamos perguntado ainda sobre furtos de canoas a ele e que vínhamos fartamente encontrando na imprensa. Mas, sobretudo, Francisco parecia querer de imediato defender a serenidades e honestidade de seu tempo. Nas memórias dos entrevistados, não existia espaço e sentido para os "desabusados piratas" dos jornais nos quais levantamos 94 crimes de furtos, contrabandos e desvios de mercadorias, jogatina, brigas, etc., pelas margens e águas de Manaus e que punham a prova o tranquilo sono de Francisco.

No que tange aos furtos, as embarcações amazônicas, sobretudo as menores como canoas e catraias, sempre foram os maiores alvos dos gatunos. Como cultura material: instrumento de locomoção, fonte renda e lugar de moradia (ou pousos) as embarcações amazônicas tem também um sentido afetivo para seus proprietários como nos indicou a "Morena", canoa furtada e intensamente procurada por Joaquim Manoel de Oliveira, comentado acima.

\footnotetext{
${ }^{14}$ Entrevista. Manaus, I5 de setembro de 2008.
} 
Por tudo isso, são amplamente desejadas pela população local, cuja maioria não tinha destreza para a construção de uma canoa, ou não possuíam recursos para a compra nos “(...) afamados estaleiros de Santarém (...), com uma filial agora em Manaus, segundo reclame da época que, um outro, prometia "Preços vantajosos" para seus batelões e canoas "De todos os tamanhos e feitios material solido e perfeito acabamento". I5

Cobiças, eventualmente, satisfeita através dos vários furtos ocorridos nas margens, rampas e portos da cidade como os que vitimaram José Fernandes e o catraieiro Sabino Ferreira. O primeiro, mesmo mantendo-se vigilante para com sua canoa, teve “(...) esse tão útil objeto (...)" furtado das margens do igarapé dos Artigos Bélicos. Sabino Ferreira também teve “(...) a menina dos seus olhos (...)” surrupiada do Porto das Catraias nos igarapé dos Educandos onde “(...) passava grande parte do dia a trafegar de uma margem para outra (...)” atravessando pessoas entre o bairro de Educandos e o Centro, “(...) arranjando alguns borós, que davam mais ou menos, para equilibrar a sua balança financeira (...)" ${ }^{\mathrm{I} 6}$

Agora no igarapé de Manaus, "Os gatunos fizeram uma revista (...) levando dalli uma canoa pertencente ao roceiro Felix Alves de Carvalho que havia chegado do lago Anvers". Nas mesmas águas, "Os meliantes deram um bordo (...) carregaram uma canoa pertencente a José Estrumielo". Do outro lado da cidade, em 1927, no igarapé de São Raimundo “(...) furtaram as duas canoas (...) de Hypolito Martins, morador do bairro de São Raimundo que, três depois, voltaria a delegacia do bairro para denunciar o furto de outra canoa sua! Agora no igarapé de São Vicente, tanto no primeiro, com no segundo caso, apesar das promessas policiais, nada foi feito, uma tônica na maioria dos casos. ${ }^{17}$

Nas movimentadas águas do Rio Negro, no Centro, os "larápios" e “meliantes", também não perdem as oportunidades. Da rampa do Mercado público, levaram a canoa de Antonio dos Reis que, além de seu objeto de locomoção, perdeu ainda “(...) três machados, cinco pedras de amolar, três terçados, quinze metros de fazenda e uma lata de manteiga" que estavam dentro da embarcação, despertando ainda mais a cobiça dos ladrões que também afanaram, no mesmo local, a canoa de Joaquim de Freitas. ${ }^{18}$

Nem mesmo os policiais podiam descuidar de suas embarcações como pode perceber o subdelegado Antonio Alves de Amorim que, na mesma rampa do Mercado, foi vitima dos “(...) piratas que andam em atividade febril pelas aguas de Manaus”, tanto que

\footnotetext{
${ }^{15}$ Jornal do Comércio. Manaus, “Canoas e Batelões”, o9 de janeiro de 1920 e o8 de março de I928.

${ }^{16}$ Jornal do Comércio. Manaus, "Os Buliçosos", I7 de abril e I6 de maio de 1920.

${ }^{17}$ Jornal do Comércio. Manaus, "Os Buliçosos", 03 de novembro I920, 29 de janeiro de I922, I7 de maio I927 e 07 de maio de 1930.

${ }^{18}$ Jornal do Comércio. Manaus, "Os Buliçosos", 22 de fevereiro de 1922 e 02 de fevereiro de I927.
} 
surrupiaram sua “(...) canoa de itaúba, com 30 metros de comprimento, por 20 de largura (...)”. O policial, para espanto da imprensa, “(...) não sabe a quem atribuir a autoria do furto". ${ }^{19}$

Distante um pouco no tempo, mas não no espaço, nos encontramos de novo no Rio Negro, centro, agora no Porto das Catraias na Rua dos Andradas em 1947, as voltas com mais um furto de canoa, pertencente à senhora Guilhermina Cardoso que denunciou o caso ao GIC que, diferente dos casos anteriores, tomou providencias imediatas para o caso e, mais surpreendente ainda, achou a canoa na ilha de Monte Cristo, próxima ao Porto.

A julgar pela descrição da canoa de dona Guilhermina: “(...) equipada com um motos 'Arquimedes', de 6 cavalos, registrada na Capitania dos Portos (...) pintada de azul (...)", obra, quem sabe, de um dos “afamados estaleiros" da propaganda acima, e pelas ações rápidas e eficazes ações da polícia, dona Guilhermina parecia gozar de uma posição socialmente privilegiada em relação a maioria das outras vitimas do mesmo crime, como o senhor Hypolito Martins, que também denunciou os furto de suas três canoas, mas não recebeu a mesma atenção policial.

Outra modalidade de furto eram os que ocorriam a bordo, envolvendo aí os casos de desvio de mercadorias e contrabando que pareciam não atingir, ou não sensibilizar Sebastião Garcia que nos contou das várias madrugadas em que, com o cunhado, ia de canoa comprar hortaliças na "frente de Manaus". Enquanto esperavam pelos plantadores ribeirinhos, nos afiançou Sebastião: "cansamo de deitar no porão da canoa, ficava até o sono chegar, com o dinheiro no bolso e nunca ninguém via esse negócio de roubo". ${ }^{20}$

Bernardo Ghisermanis, recém-chegado em um navio vindo de Belém, enquanto esperava o desembarque, como Sebastião Garcia, também resolveu tirar um sono, mas não teve a mesma sorte do nosso entrevistado, “(...) foi roubado em um conto e duzentos mil réis que estava no travesseiro" não conseguindo perceber as habilidosas ações dos gatunos. ${ }^{2 \mathrm{I}}$

Diferente dos furtos de canoa, os de furto a bordo, traziam mais informações dos criminosos, nos permitindo delinear melhor o rosto social dos nossos "piratas". Esses maiores detalhes se davam pelo maior valor das mercadorias furtadas como couros e peles, castanha, juta e borracha que comumente interessavam a Alfandega do Estado e a Associação Comercial do Amazonas (ACA) que tinham um maior poder de cobrança junto as autoridades policiais, tanto que no inicio de 1933 os “(...) srs. exportadores de castanha (...)" pediram para que a ACA intercedesse junto a superintendência da Manáos Harbour, no

\footnotetext{
${ }^{19}$ Diário da Tarde. Manaus, "Policia e Ruas", 27 de dezembro de I940. Grifo nosso.

${ }^{20}$ Entrevista. Manaus, 20 Nov 2009.

2I Jornal do Comércio. Manaus, "Os Buliçosos”, ı Mar 1935.
} 
sentido de “(...) reforçar a illuminação dos fluctuantes onde estacionavam as alvarengas de castanha, afim de evitar furtos do producto armazenado, durante a safra, a espera de conducção para o estrangeiro". O pedido foi pessoalmente conduzido pelo Presidente da ACA. ${ }^{22}$

As medidas eram para pelo menos dificultar os constantes assaltos a bordo das embarcações que, desde a década anterior, inquietavam a população e já estavam prejudicando os negócios oficiais. Do "magnifico batelão” de Antonio da Costa “(...) amarrado no igarapé dos Educando” levaram “(...) umas latas de biscoito, goiabada e manteiga", quase uma iguaria para a maioria dos moradores e mercadoria cara vendida na praça comercial da cidade. ${ }^{23}$

Mais cobiçados ainda foram os “(...) dois paneiros de castanha”, furtados por Damião da Silva do batelão do seu patrão, Melchior Telles que o denunciou a policia. Preso, Damião confessou o furto e o repasse da castanha para dois catraieiros. Confirmando os temores da ACA, os "piratas do rio" atacaram o armazém vinte da Harbour, de onde “(...) desappareceram cento e vinte e três saccos de estopinha nova no valor total de quinhentos sessenta e cinco mil oitocentos réis"; para o caso a delegacia auxiliar "prometeu agir". ${ }^{24}$

Não muito distante dos armazéns da Harbour, na cada vez mais perigosa rampa do Mercado Público "Os ladrões, na madrugada, deram em um batelão (...) carregaram dalli a quantia de cento quarenta e cinco mil reis, pertencente a José Gonçalves Pereira" que responsabilizou pelo furto Honorato Guimarães Barbosa e Raymundo Guimarães, que haviam ficado no batelão, ambos “(...) conduzidos á delegacia auxiliar, onde ficaram detidos para effeito de averiguações". ${ }^{25}$

A véspera das reclamações dos diretores da ACA sobre a escuridão que acomete os armazéns do Porto, os assaltos a bordo persistem. Para tanto, retomemos a noticia sobre "os ratos do porto” que agora agiram “(...) contra o sr. João Barbosa, tripulante da lancha 'Theolinda' (...) que de bordo do batelão "Ena”, atracado ao costado daquella embarcação fluvial, surta no igarapé dos Educandos (...) os 'lunfas' furtaram um relógio marítimo (...). Tanto as ações dos "lunfas", quanto o destino do relógio, permanecem "mysteriosos" para a polícia que, como conclui o registro jornalístico:

\footnotetext{
${ }^{22}$ Manáos, A illuminação dos fluctuantes interior da M.H.Ltd. Revista da ACA, 25 Jan I933, Anno XXIII (3a phase), $\mathrm{n}^{\circ}$ I92, página não numerada. Grifo nosso.

${ }^{23}$ Jornal do Comércio. Manaus, "Os Buliçosos", 07 de setembro de 1920.

${ }^{24}$ Jornal do Comércio. Manaus, "Os Buliçosos", 22 de maio de 1922 e 28 de agosto de 1924.

${ }^{25}$ Jornal do Comércio. Manaus, "Os Buliçosos”, I5 de maio de 1930.
} 
Repetem-se ultimamente, assaltos audaciosos, levados a cabo, com invulgar maestria em vapores e "gaiolas" ancorados nas immediações do porto, pelos braços navegáveis adjacentes. Grande parte desses delictos tem ficado impune, parecendo que se trata de uma quadrilha perfeitamente organizada, agindo pelas caladas da noite. ${ }^{26}$

Em um desses "braços navegáveis adjacentes” encontramos “(...) a lancha Cidade de Alemquer (...)" que “(...) transpoz, hontem, a bocca do Solimões, entrando no rio Negro, com um carregamento de cerca de I.80o arrobas de pirarucu”. Mercadoria das mais valiosas, tanto por sua carne, quanto pelo seu coro que “(...) não chegou a Manáos, sendo desembarcada clandestinamente em um batelão, na foz do Xiborena, com evidente prejuízo do fisco e do commercio desta praça”, para o qual a imprensa cobra investigações e punições do "(...) responsável pelo contrabando”, ${ }^{27}$ ou responsáveis, talvez outras das ações de "pirataria" da "quadrilha organizada" do "Registro Policial" acima, cujos atos criminosos, aliás, são contemporâneos ao caso de contrabando do pirarucu.

De bordo do vapor Adamastor foram furtados também “(...) I6 couros de gato, artigo de primeira qualidade, cotado a excellente preço" no mercado internacional para onde eram habitualmente destinados. Depois de alguns dias, os policiais, segundo a imprensa, chegaram aos culpados, tratavam-se dos “(...) marinhos daquele navio, Francisco de Souza e Luiz Miranda (...)" que confessaram o delito, mas de apenas 4 couros, os outros I2, segundo os detidos, competem a um outro marinho, de nome Aureliano que, segundo a policia, “(...) se escafedeu com a primeira canoa que estava ao alcance de suas mãos” na praia do Mercado. $^{28}$

O entorno do Mercado Público: rampa, porto, praia e águas, na década de quarenta, tinham se transformado em um território propício a gatunagem, furtos, contrabandos e outras contravenções que estampavam as crônicas policiais, como "O malandro e ladrão" que dizia respeito a Wilson de Sousa, preso com grande “(...) quantidade de mercadorias, que fora roubada dos armazéns da Manaus Harbour e de bordo do vapor Cabedelo (...)”. Já em o "Lunfa de praia” chegamos a Carlos Jaime Martins “(...) de cor escura, forte, de I9 anos de idade, sapateiro nas horas vagas (...)", mas nas "não vagas", a noite, pirateava sacas de farinha de embarcações na praia e rampa do Mercado, águas do Rio Negro no Centro, crime pelo qual foi recolhido a prisão. ${ }^{29}$

\footnotetext{
${ }^{26}$ O Jornal. Manaus, "Registro Policial”, o7 de julho de 1932.

${ }^{27}$ O Jornal. Manaus, "Desembarcou a mercadoria clandestinamente", or de novembro de 1932.

${ }^{28}$ O Jornal. Manaus, "Policia \& Ruas", 20 de março de 1936.

${ }^{29}$ Diário da Tarde. Manaus, o4 de fevereiro e or de março de I947.
} 
Outro "pirata" que agia nas horas vagas e não vagas era Francisco Januário, de 29 anos de idade, preso pela policia, quando trabalhava como carregador no igarapé dos Educandos, também por furto de farinha na praia e rampa do Mercado. Sua prisão resultou das muitas queixas apresentadas a policia pelos vendedores ambulantes daqueles lugares, cansados dos “(...) dos constantes furtos de mercadorias (...) responsáveis pelos grandes prejuízos que veem sofrendo nesses últimos tempos", final da década de quarenta, de constantes sobressaltos provocados por "lunfas", "malandros" e "piratas" que, segundo os vendedores e a imprensa, estavam transformando aquelas margens em "valhacoito de ladrões e salteadores". ${ }^{30}$

Mesmo alguns dos nossos entrevistados se renderam, um pouco, a cidade nervosa das folhas jornalísticas. A certa altura da conversa com Vivaldo Correa, verticalizei as questões de segurança pública nas imediações da orla central, "ali na área do Mercado", precisou Vivaldo. Foi quando a cidade pacata e saudosa das recordações dos entrevistados sofreu algum abalo, "No Mercado Grande existia né alguns roubos e essas coisas aí". 3I

\section{A Manaus dos flutuantes: a cidade dos "piratas"}

Vivaldo Correa a partir de 1949 foi morar em uma casa flutuante na Cidade Flutuante de Manaus, ${ }^{32}$ um fenômeno social e urbano que começou timidamente por volta da década de vinte com algumas casas dispersas pelo Rio Negro e igarapés da capital, mas que ao longo da década de cinquenta foi se transformando em um complexo urbano e social de casas, comércios, vias, pontes que, em seu auge, inicio da década de sessenta, chegou a abrigar mais de 12 mil moradores distribuídos por mais de 2 mil habitações flutuantes, assumindo "ares" de uma verdadeira cidade, batizada pelos moradores e imprensa de "Cidade Flutuante", até ser completamente desmantelada pelo governo amazonense, com total apoio da Capitania dos Portos em I967 (BARATA SOUZA, 20IO, p.I8).

Então a situação, pós-I950, havia mudado bastante: casas e comércios flutuantes, também se multiplicavam sobre as águas. Os abertos espaços de antes se compactavam na forma de vias, pontes, ancoradouros e becos, formando um complexo labiríntico por onde pulsavam serviços e negócios e, por isso, também um novo território promissor para furtos e roubos, bem como para fugas e refúgios dos "piratas", o que preocupava ainda mais as

\footnotetext{
${ }^{30}$ Diário da Tarde. Manaus, o7 Dez 1948 e A Crítica. Manaus, I2 de junho de I95I.

${ }^{3 \mathrm{I}}$ Entrevista. Manaus, oI de outubro de 2008.

${ }^{32}$ Dos nossos I4 entrevistados, o9 foram moradores da Cidade Flutuante de Manaus.
} 
autoridades policiais e os negociantes, especialmente do comercio legal em terra, mesmo a tradicional ACA.

As "guerras relâmpagos" da policia pela orla de Manaus, segundo a imprensa e a despeito das graves condições financeiras do Estado, nunca deixaram de acontecer. Essas incursões visavam salvaguardar um espaço estratégico da cidade, seu porto de entrada e saída de pessoas e mercadorias e posto alfandegário do estado.

O revigoramento técnico e pessoal do Gabinete de Inspeção e Capturas (GIC), visando melhorar e estender o policiamento da capital e, sobretudo, a criação em 1950 da Polícia Portuária para combater os roubos a bordo de Mercadorias e das docas da Harbour, são índices dessas preocupações oficiais registrados nos Boletins da ACA, cujos diretores passam a organizar uma campanha e a interferir de forma mais enérgica contra as pilhagens das mercadorias exportáveis pelo Porto de Manaus, o que comprometia as receitas oficiais e seus lucros pessoais.

Nestes termos, pelos boletins da entidade de 1950, foram publicizadas a nervosa situação de segurança da cidade e para qual, estamos certo, concorreram os "piratas do rio" com suas ações de furto e contrabando, facilitadas e incentivadas agora pela proliferação de casas e comércios flutuantes pelas águas de Manaus:

Prosseguiu, no mês de janeiro, a campanha contra o roubo de mercadorias (...) causando grandes prejuízos ao comércio importador. Na sede social, houve uma reunião de elementos oficiais e particulares, a fim de tomar providências relacionadas com os constantes roubos e desvios de mercadorias no porto desta capital. Nessa reunião ficara acertada a colaboração da associação, para alargamento de medidas coercivas de tão criminoso abuso (...). Foram adotadas varias medidas de proteção contra furtos, reforçando o policiamento, a bordo dos navios. ${ }^{33}$

Ainda que dissimulado nos discursos da Associação Comercial, os receios dos diretores da ACA eram resultados da intensa reorganização social em processo por todo o litoral da cidade, cada vez mais repleto de moradores, comerciantes e trabalhadores tanto nas margens, rampas e portos em terra como, agora, também em flutuantes onde moravam e trabalhavam com os mais variados produtos, desde os comestíveis, que não eram o alvo

\footnotetext{
${ }^{33}$ Desvio de Mercadorias. Boletim da ACA. Manaus, Fev 1950, pg. 08 e "Policiamento do Porto", Out 1950, p. o9. Grifo nosso.
} 
das preocupações da ACA, até as valiosas especiarias extrativas vendidas, produtos de exportação, estes sim, a fonte das "medidas coercivas" do Estado e dos diretores da ACA.

Se na documentação da ACA as incriminações e discriminações aos flutuantes estavam nas entrelinhas, elas apareceram com toda força nas linhas da imprensa local, potencializando os furtos a bordo, desvios e contrabando de mercadorias que minavam as combalidas receitas do estado, prejuízos que se faziam sentir, nomeadamente, sobre os muitos diretores e proprietários dos jornais locais, muitos também membros da ACA, diretos ou indiretamente também ligados aos negócios de exportação.

Dos 94 crimes levantados na imprensa de Manaus, 22 envolviam as casas e comércios flutuantes de Manaus e isso desde seus instantes iniciais na década de vinte, agravando-se a medida que os flutuantes se adensavam sobre as águas da cidade. Envolvimento este que seguia as mais diferentes situações: vítimas de assaltos e furtos, entreposto de contrabando, esconderijos de criminosos, etc., para tanto, retomamos as pegadas da imprensa local.

Em 1920, uma briga generalizada entre embarcadiços em frente ao prédio da alfândega foi destaque nas crônicas policiais do Jornal do Comércio. Todos os brigões acabaram indo parar na “(...) na delegacia auxiliar, em cujo xadrez ficaram ancorados". Mesmo destino teve quatro estivadores que "(...) cahiram de murros no catraieiro Francisco Manoel de Abreu, residente em um flutuante estacionado no igarapé de São Vicente”. ${ }^{34}$

Por outras águas, de bordo de “(...) fluctuante que demora na foz do Xiburena (...)” foram furtado quinhentos mil reis, pertencentes ao vendedor ambulante José Maria de Andrade, proprietário do flutuante. “(...) Foram presos hontem no mercado público, os typos Joaquim Azevedo Cunha e João Alves Brandão, accusados do furto (...)”. Não muito distante dali, nas águas do paraná do Careiro, Raymundo Anastacio foi também acusado de “(...) surrupiar de um café fluctuante (...) quatro mil e trezentos réis. “(...) o marreco foi mandado para a delegacia auxiliar (...)".35

Outra nota do Jornal do Comércio de 1925 nos levou a patrulha contra pescadores "dynamiteiros" comandada pelo Capitão dos Portos Mello Pinna que, de regresso a Manaus, fez uma incursão nas águas da Ilha do Catalão ( $\mathrm{IO}^{\circ}$ distrito do Careiro), surpreendendo em um café flutuante ali estacionado, o jogo, a bebida, o roubo e as doenças que, segundo a imprensa, depunham contra o bom viver e, por isso, condenaram o flutuante a destruição.

A seguir, maiores detalhes do acontecido na Ilha do Catalão:

\footnotetext{
${ }^{34}$ Jornal do Comércio. Manaus, Coisas Policiais de 13 de outubro de 1920 e 29 de dezembro de 1928.

${ }^{35}$ Jornal do Comércio. Manaus, 05 de janeiro e II de junho de 1924.
} 
Quando regressava a Manáos, o commandante Pinna fez parar a lancha na bocca do Catalão e, penetrando no café fluctuante, que alli estaciona, teve occasião de verificar que o que lá se pratica é o jogo de azar em grande escala, havendo em deposito duchas de cabo de arame e um ancorote, cuja proveniência o proprietário do fluctuante não soube explicar, presumindo-se que taes materiaes seja producto de algum roubo.

Alem disto, o dono do fluctuante apresentava visíveis signaes do mal de Hansen, pelo que o commandante Mello Pinna ordenou a immediata destruição do fuctuante, em beneficio da saúde publica. ${ }^{36}$

Somando-se aos ilegais jogos de azar, desde as primeiras noticias sobre flutuantes, estes costumeiramente foram alinhavados como território de crimes, imoralidades e insanidades. O café flutuante acima, é noticiado pelo JC a luz de suspeitas de furto dos produtos negociáveis ali e de procedência ignorada, especialmente o "ancorote", pequeno barril usado para acondicionar a procurada e condenada cachaça consumida durante as apostas flagradas por Mello Pinna. Não foi apenas "em beneficio da saúde pública" que o Capitão dos Portos Mello Pinna botou abaixo o café flutuante da ilha. Entrecortada ao mal de hansem, um conjunto de outras sociabilidades ali denunciadas pela imprensa como o jogo, a bebida e os furtos, também contribuíram para a destruição daquele flutuante de comércio.

A "Policia e Ruas" do Diário da Tarde de 1940 noticiou que na vila do Careiro ocorreu “(...) pancadaria grossa, num dos fluctuantes que lá existe (...)” promovida pelo roceiro Joaquim Cruz, segundo a nota, “(...) em completo estado de embriaguez”. Meses depois, o mesmo jornal noticiaria, em grande destaque, o fim das "Aventuras de um negro tenebroso", de nome Salomão acusado de diversos assassinatos e roubos praticados por vários rios e margens da "Região de Manaus" e para além desta. Salomão foi preso em seu esconderijo, um flutuante estacionado nas águas do Paraná Autaz-mirim, quando foi cercado e preso pela polícia, sendo conduzido à capital. ${ }^{37}$

Tangenciando as matérias jornalísticas sobre os acontecimentos em flutuantes, mesmo quando as vítimas eram os próprios comerciantes e/ou moradores, se nota em destaque ou nas entrelinhas, os flutuantes como territórios propícios aos roubos, furtos, promiscuidades, insanidades, doenças e a velhacaria; covil onde se escondem malfeitores e

\footnotetext{
${ }^{36}$ Jornal do Comercio. Manaus, "O capitão dos portos em repressão aos pescadores a dynamite e outros infractores do regulamento da pesca - As jangadas -", I2 de setembro de I925. Grifo nosso.

${ }^{37}$ Diário da Tarde. Manaus, "Policia e Ruas" o8 de abril e 2I de outubro de I940.
} 
fugitivos. Selo condenatório este mantido na capital e potencializado pela Cidade Flutuante.

A década de trinta mal começara e as páginas da imprensa local estão as voltas, mais uma vez, com os "piratas do porto" que, dessa vez atacaram o próprio almoxarifado da Manáos Harbour. Dali, segundo comunicação do gerente da concessionaria, “(...) os amigos do alheio (...) surrupiaram dez caixas de Kerozene marca Jacaré”, as quais, depois de rigorosas investigações e diligências pelo litoral da cidade, foram encontradas “(...) em um fluctuante nos Educandos". ${ }^{8}$

A lista de "Um furto a bordo do Baependy" é bem extensa:

(...) Três fardos de charque, duas latas de azeite de oliveira (...) duas de tinta branca, uma sacca com toucinho, jabá e feijão preto, uma lata de banha de vinte Kilos, uma de café moído, uma de compota, duas de leite Moça e vinte cinco de liquido para limpeza de metaes, avaliados na importância de novecentos e cincoenta e nove mil e cem reis (...).

Todas essas mercadorias foram encontradas pela polícia no "[...] café fluctuante de Raymundo Gomes Soares, por alcunha Raymundo Capivara [...]". A polícia chegou até o comércio flutuante de Raymundo Soares através da “(...) denuncia do mercieiro Manoel Pereira de Souza (...)" que falou às autoridades que as mercadorias foram levadas ao café flutuante “(...) pelo meliante Francisco Macedo, vulgo Chico Ratinho (...)”, este, por sua vez, segundo as investigações policiais, obteve os produtos por intermédio do desvio feito pelo "paioleiro" Manoel Soares, trabalhador a bordo do paquete "Baependy", 39 animando uma rede de desvio de mercadorias que começava pelas mãos de tripulantes das embarcações e terminava no comercio da cidade.

De fato, nem o "Kerozene" levado do almoxarifado da Harbour e nem as várias mercadorias desviadas do "Baependy", estavam na "lista" dos produtos de exportação amazonense vigiada e controlada pelas autoridades locais, sobretudo pela ACA, mas representava moeda de troca certa dos regatões e donos de estabelecimentos flutuantes junto aos extratores da hinterlândia amazônica.

Mário Ypiranga Monteiro, cujos estudos sobre os regatões também chegaram a esse novo período, nos informa que “(...) os grandes regatões (...) transacionam com casas

\footnotetext{
${ }^{38}$ Jornal do Comércio. Manaus, "Os Buliçosos”, i4 Set 1932. Grifo nosso. O JC informou ainda que os artífices do furto foram “(...) os conhecidos larápios João de Oliveira Castro, vulgo João dos telhados e Cyriaco de tal (...)”, sendo ambos presos na cidade de Itacoatiara, interior do Estado.

${ }^{39}$ Jornal do Comércio. Manaus, I5 de novembro de i939. Grifo nosso.
} 
comerciais aviadoras de Manaus, levando mercadorias consignadas (...)", cuja lista do autor traz: açúcar, sal, feijão, café, arroz, carne enlatada, cachaça, pirarucu, combustível, lampiões a querosene, doces em lata, carne seca salgada em mantas, trigo, calçados, fazendas, produtos utilizados na permuta por “(...) juta, sorva, balata, castanha, borracha, essências, etc. [...]" (MONTEIRO, I958, p. 32 e 34-35) e as valiosas peles e couros dos animais, estes sim, de amplo interesse da ACA e que, para o desespero de seus diretores, também começaram a ser "transacionadas" em flutuantes comerciais em franca expansão sobre as águas.

Em 1947, os jornais de Manaus deram ampla cobertura a mais um furto a bordo de um motor estacionado na Ilha de Caxangá, Igarapé de Manaus, de onde foram roubados, segundo lista do Diário: “(...) 8 couros de queixada, 5 tracajás e tartarugas, 2 latas de combustol e uma pele de borracha (...)" pertencentes a Artur Bezerra, dono do motor, que pediu providências ao Gabinete de Investigações e Capturas da polícia.

Depois das diligências perto do igarapé, os investigadores prenderam o paraense Manoel F. dos Santos, “(...) sem profissão e sem residência (...)” que teria confessado o roubo e não apenas das mercadorias elencadas no Diário, mais ainda: "[...] pele de borracha, com 5I quilos, 2 lanternas, I maçarico [...]”. Os couros de Artur Bezerra foram encontrados no Mercado Público na banca de José M. Cardoso, “(...) preso como receptador de furto (...)”; os combustíveis e o tracajá estavam com “(...) um tal de Bidá, residente em um flutuante, localizado no Paraná da Terra Nova", distrito de Manaus, e as borrachas foram apreendidas “(...) no flutuante de Aprígio de tal, localizado na boca do igarapé dos Educandos". ${ }^{\circ}$

A mencionada blitz-Krieg de 1948 capturou o "lunfa" José Bernardo da Silva, maranhense, "[...] residente em um flutuante localizado no igarapé dos Educandos [...]". Esperava a polícia que tal prisão "[...] possa fazer alguma luz sobre o tenebroso mistério que envolve esses assaltos", sobretudo pela orla da capital, ${ }^{4 \mathrm{I}}$ ledo engano.

O comerciante Paulo Pinto tinha um comércio sobre as águas no Igarapé dos Educandos onde, como alegou à polícia, fora vítima do furto de quase todas as suas mercadorias: “(...) cinco pelles de lontra, sete de maracajá, uma de onça e mais ou menos cem ditas de camaleão, as quaes, se encontravam no dito fluctuante”.

Paulo Pinto disse na polícia que suspeitava de José Firmo, residente na Avenida Joaquim Nabuco no Centro que, por sua vez, em sua defesa alegou ter comprado as peles de um "desconhecido" que sabia apenas ser de nacionalidade peruana. As desculpas não

\footnotetext{
${ }^{40}$ Diário da Tarde. Manaus, "Apreendidos produtos de um roubo", 23 de outubro de 1947. Grifo nosso.

${ }^{4 \mathrm{I}}$ Diário da Tarde. Manaus, "Preso um celebre lunfa maranhense", 02 de fevereiro de 1948.
} 
convenceram nem Paulo Pinto e muito menos a polícia que prendeu José Firmo “[...] afim de melhor apurar o facto".

José Firmo ficou preso até o dia seguinte quando entregou o nome do peruano Carlos Gonzáles que foi preso de madrugada “(...) na praia do Mercado (...)” Público. Gonzáles da Silva, a princípio, negou o roubo se dizendo carpinteiro, mas acabou confessando a investida noturna contra o flutuante comercial de Paulo Pinto, levando os policiais a sua casa, “(...) um quarto (...) próximo ao rio (...)” Negro onde estava “(...) grande parte do producto roubado". ${ }^{42}$

A imprensa da época denunciava "Estrangeiros Clandestinos se infiltrando em Manaus, em grande numero" que vinham nos porões dos navios que faziam a linha de Iquitos e Letícia para Manaus, ou desciam o rio nas próprias canoas. Todos, segundo a reportagem, “(...) elementos suspeitos, geralmente em situação irregular (...)” que veem se esconder na cidade, sobrevivendo de meios ilícitos, engrossando o "caldo social" já em ebulição pelas águas, portos, margens e rampas da cidade. ${ }^{43}$

Nosso entrevistado, Vivaldo Correa, nos contou sobre alguns "contrabandos" de arroz, uísque e, especialmente de cebola trazidos pelos marítimos peruanos e colombianos para os comerciantes em terra da Rua Barão de São Domingos, "fregueses certos", garantiu Vivaldo, “(...) tem tantos sacos de cebola pra fulano, tanto sacos de arroz pra fulano, tantas caixa de uísque pra fulano (...)" ${ }^{44}$

Verdade que a maioria dos entrevistados não deixou de mencionar uma ou outra desordem, suscitar alguns roubos, furtos, discussões, palavrões e brigas, mas nada de muito sério, eles, em regra, seguiam defendendo a quietude de seu lugar e de seu tempo.

Por outro lado, como sempre buscamos uma cidade a "contrapelo", voltamos novamente às entrelinhas da oralidade, confrontando-as com a fala jornalística, para surpreendermos algumas disputas e contravenções que possam, de alguma forma, por a prova a costumeira paz lembrada.

No limiar da década de cinquenta, a costumeira quietude da "cidade flutuante", defendida pelos nossos entrevistados, passou a ser sacudida por acaloradas concorrências comerciais, levando Vivaldo Correa a retomar a "cidade flutuante" em tons menos bucólicos:

\footnotetext{
${ }^{42}$ Jornal do Comércio. Manaus, "Os Buliçosos”, 29 e 30 Out 1949.

${ }^{43}$ Diário da Tarde. Manaus, I8 de Janeiro de 1947.

${ }^{44}$ Entrevista. Manaus, o6 Mar 2008.
} 
Aqueles comerciantes que era estabelecido lá em terra, o pessoal do interior que trazia mercadoria, a mercadoria deles já num chegava mais pra eles, quando já ia chegar já era pela mão de terceiro, entendeu? Lá ("cidade flutuante") já tinha também flutuante que comprava, já tinha é pessoa que tinha condição financeira boa né e já comprava já, abria lá um flutuante pra compra borracha, castanha, seringa, tudo que vinha do interior (...) num dava pra chegar pra lá pra eles (comércio em terra), o pessoal da cidade flutuante é que oferecia um preço melhor né, aí o pessoal, o interior num ia, tá entendendo, o pessoal do interior num ia botar no ombro pra leva lá pra vender pelo mesmo preço, ficava ali mesmo, entregava ali mesmo. O comerciante lá de terra num comprava mais, encostava no seu flutuante aí ele: "rapaz eu dou tanto" que era pra num leva lá pro comerciante lá em cima né, ele já botava o preço dele, aí o caboco chegava ali já cansado, "rapaz não vou carrega essa mercadoria...", pronto vamos fazer negócio. Naquele tempo vendia muita pele de animal né, couro de porco, de veado, tudo, eles compravam tudo (...) o negócio era grande!

Pelas mais variadas formas e caminhos, os flutuantes, agora já uma "cidade sobre as aguas", começaram a negociar também com as preciosas especiarias extrativistas que, com grande dificuldade, conseguiam ainda manter o erário amazonense, sendo por isso, mais uma vez, alvo das denúncias na imprensa da época e das ações policiais que se voltaram diretamente contra ela e seus moradores, quase todos resumidos a imagens de contraventores, portanto, "piratas" em potenciais, um dos fatores que contribuiria para seu desmantelamento, entre 1964 e I967, celebrada pela imprensa local:

A "Cidade Flutuante", mostrengo inóspito que vinha crescendo a ourela do Rio Negro, ao lado do porto de Manaus, além de famílias necessitadas, abrigava também um viveiro de contrabandistas de produtos regionais (...) sempre foi um dos caminhos para as negociatas e o contrabando. ${ }^{45}$

\footnotetext{
${ }^{45}$ Diário de Noticias. Manaus, 22 de março de 1966 e A Crítica. Manaus, abril de 1966. Grifo nosso.
} 


\section{Conclusão}

“(...) agora me tragam o horizonte (...)”.46

Recuperando a epígrafe inicial do artigo, nossos "piratas" não se encontravam "fora do mapa", pelo contrário, estavam geograficamente dentro tinham pleno conhecimento do lugar, especialmente da "Região de Manaus", território de suas mais diferentes ações e contravenções, animando uma paisagem social que, aqui, saltaram em relevo os crimes de furtos e contrabandos a bordo, nas margens e em flutuantes planejados e praticados por homens, em sua maioria muito jovens e originários da própria região.

Socialmente também inseridos, ainda que nas margens, em suas franjas, na condição de "lunfas", "meliantes", "salteadores", "piratas desabusados", etc., legadas a eles por suas experiências criminosas denunciadas na imprensa, nos boletins da ACA e pelas "guerras relâmpagos" da polícia pelo litoral da cidade, quando abriam caça aqueles transgressores.

Se eram "monstros"? Na imprensa sem dúvida, personagens bem reais de suas crônicas policiais, moradores inclusive de "monstrengos inóspitos" como a Cidade Flutuante. Para as narrativas orais, eles quase não existem incompatíveis que são com cidade pacata e ordeira, habitualmente lembradas pelos entrevistados.

Para o autor, nem "monstros", nem vilões, nem heróis, mas sujeitos históricos, cujas experiências nos oportunizaram discutir algumas experiências criminosas ocorridas em uma região e um tempo onde tais temas ainda estão em seus primeiros passos. Esse artigo visou contribuir para essa caminhada, propondo, enfim, que no horizonte das pesquisas locais possam ser também vislumbrados os "piratas do rio".

\section{Referências Bibliográficas}

BARATA SOUZA, Leno José. Cidade flutuante, uma Manaus sobre as águas: 1920-1967. Tese de Doutorado em História, Pontifícia Universidade Católica de São Paulo. São Paulo, 20 Io. BITTENCOURT, Agnello. Corografia do Estado do Amazonas. Manaus: ACA, 1985.

DEFOE, Daniel. Uma história dos piratas. Rio de Janeiro: Jorge Zahar, 2008.

GOUROU, Pierre. Observações geográficas na Amazônia. Revista Brasileira de Geografia, n. ${ }^{\circ}$ 3, Julho/Setembro de 1949.

\footnotetext{
${ }^{46}$ Trecho final do filme "Piratas do Caribe: a maldição do Pérola Negra" de 2003.
} 
HOBSBAWM, Eric J. Bandidos. São Paulo: Paz e Terra, 2010.

MAXWELL, Kenneth. Chocolate, piratas e outros malandros: ensaios tropicais. São Paulo: Paz e Terra, 1999.

MENDONÇA, Carlos. Ângulos do Problema Amazônico (I942). Manaus: Biblioteca Pública do Estado do Amazonas, 2002.

MONTEIRO, Mario Ypiranga. O regatão. Manaus: Sérgio Cardoso \& Cia Ltda, 1958.

RUDÉ, George. A Multidão na História: estudo dos movimentos populares na França e na Inglaterra, I730-I848. Rio de Janeiro: Campus, I99I.

SOARES, Lúcio de Castro. Amazônia. Guia da Excursão $N^{\circ}$ o8, realizada por ocasião do XVIII Congresso Internacional de Geografia. Edição do Conselho Nacional de Geografia, Rio de Janeiro, 1963. 